\title{
A Study of Intracoronary Injection of Hematopoietic Stem Cells in Pediatric Dilated Cardiomyopathy: Is It an Applicable Solution for Critically Ill Patients?
}

\author{
Hamid Amoozgar ${ }^{1}$, Mohammad R. Edraki ${ }^{1}$, Maryam Ayatollahi ${ }^{2}$, Mohammad Borzouee ${ }^{1}$, \\ Gholamhossein Ajami ${ }^{1}$, Hamid Mohammadi ${ }^{1,{ }^{*}}$, Nima Mehdizadegan ${ }^{1}$, Nader Shakibazad ${ }^{3}$, Hamid \\ Arabi ${ }^{1}$, Fatehi Alwesabi ${ }^{1}$, Amir Naghshzan ${ }^{1}$ and Kambiz Keshavarz ${ }^{1}$ \\ ${ }^{1}$ Neonatology and Cardiac Research Center, Shiraz University of Medical Sciences, Shiraz, Iran \\ ${ }^{2}$ Transplant Research Center of Shiraz University of Medical Sciences, Shiraz, Iran \\ ${ }^{3}$ Hematology Research Center, Shiraz University of Medical Sciences, Shiraz, Iran \\ "Corresponding author: Pediatric Cardiology Ward, Namazi Hospital, Shiraz, Iran. Tel: 071-36125660. Email: mohammadi219@gmail.com
}

Received 2018 August 17; Revised 2018 December 26; Accepted 2019 January 09.

\begin{abstract}
Background: Benefits of stem cell therapy on remodelling and cardiac function have been described in adults with dilated cardiomyopathy and acute myocardial infarction.

Objectives: We investigated the effect of this treatment modality amongst children with severe dilated cardiomyopathy. Methods: Intracoronary injection of autologous bone marrow mononuclear stem cells was performed in our centers for 8 severely ill children during 2015 - 2016. The mean age of the patients was 10.1 years ( 5 girls, 3 boys). They were followed by longitudinal speckle tracking echocardiography (STE) and conventional echocardiography for 6 months.

Results: Heart functional class improved in $62 \%$ of patients. M-mode echocardiography showed significant improvement in ejection fraction (mean $24.8 \pm 8.3$ vs. $37.4 \pm 10.5$ ) and in STE, the mean global longitudinal strain improved (GLS: $-2.8 \pm 1.9$ vs. $-5.2 \pm 3.9$ ). None of the patients had serious complications.

Conclusions: Intracoronary injection of autologous mononuclear stem cells might improve the ventricular function and cardiac remodelling in pediatric patients with dilated cardiomyopathy and could be considered in critically ill patients.
\end{abstract}

Keywords: Dilated Cardiomyopathy, Stem Cell Therapy, Speckle Tracking Echocardiography

\section{Background}

Dilated cardiomyopathy results in considerable morbidity and mortality. About $30 \%$ of the pediatric patients die within the first year after diagnosis in spite of full medical anticongestive treatment or implantation of assist devices, unless they undergo heart transplantation $(1,2)$.

Paucity of the proper donors and modest outcome of cardiac transplantation has encouraged the researchers to further investigate for alternative treatments including stem cell injection $(3,4)$. Cell-based strategies, mononuclear fraction, offer potential solutions for biological repair or regeneration of degenerated tissues. These cells contain hematopoietic stem cells, endothelial precursors, and mesenchymal stem cell progenitors $(2,5)$.

Some studies have shown some positive effects of intracoronary stem cell injection on cardiac function and remodelling in adult patients (5). More importantly, mononuclear stem cells are a major source of trophic factors, which can be harvested in a one-step procedure without the need for extensive culture procedures (6).

Although a series of studies have shown various amounts of improvement in cardiac function among adult patients $(7,8)$, few articles on intracoronary stem cell injection in children have been published (9). Nonetheless, less information is available on the assessment of this treatment with respect to speckle tracking echocardiography.

\section{Objectives}

The main objective of our trial was to assess midterm follow-up of cardiac function and remodelling after intracoronary injection of autologous mononuclear stem cells in severely ill pediatric patients with dilated cardiomyopathy. 


\section{Methods}

Between October 2016 and May 2017, we performed intracoronary injection of autologous mononuclear stem cells at two hospitals affiliated to Shiraz University of Medical Sciences, Shiraz, Iran. The authors assert that all procedures contributing to this work comply with the ethical standards of the relevant national guidelines on human experimentation of institutional and ethics committee and in accordance with the Helsinki Declaration of 1975 , as revised in 2008 , also, the study has been approved by the Institutional Committees of Shiraz University of Medical Sciences and registered on www.irct.ir (number IR.SUMS.REC.1395.81). All parents or guardians filled out a written informed consent form.

The inclusion criteria were diagnosis of dilated cardiomyopathy, left ventricular ejection fraction $<40 \%$, persistence signs and symptoms of cardiac failure at least 6 months after optimal medical therapy. All patients had a history of several hospital admissions within the past few months with intravenous inotropic medications and multiple PO or IV anti-failure drugs; However their NYHA functional class was 4 despite full treatment. The exclusion criteria were other severe organ dysfunction and malignant arrhythmia.

Echocardiographic studies were performed just before cell therapy and 6 months after the procedure. The data were analyzed statistically through SPSS version 19 using Wilcoxon test and paired $t$-test to compare the samples. $\mathrm{P}$ value $<0.05$ was considered as statistically significant.

\subsection{Echocardiography}

Transthoracic M-mode, two dimensional and longitudinal speckle tracking echocardiography by ultrasound systems (Vivid 3 General Electric and MyLab Esaote, Italy) were performed before and after 6 months of procedure.

Longitudinal strain and strain rate were calculated in 4 chamber speckle tracking echocardiography (MyLab Esaote, Italy) of the left ventricle at about 40 frames/s, while the left ventricular endocardial borders were manually traced, and then speckles tracking process was done automatically (10).

\subsection{Bone Marrow Aspiration and Processing}

Of each patient, 1 - 2 millilitres per kilogram and maximum of 40 millilitres bone marrow was aspirated from the iliac crest 3 hours before cell injection under conscious sedation and local anaesthesia under sterile conditions (11). The samples were then transferred to clean room (EU GMP grade B clean room) for cell isolation.

Each sample was diluted 1:1 with phosphate buffer saline (PBS, Clinimax, Germany), and then loaded onto
Lymphodex (Inno-Train, Germany) and centrifuged. Mononuclear cells were gently collected and washed three times with phosphate buffer saline, and prepared for intravenous injection. Cell viability was determined using the Trypan blue exclusion assay, and counted before injection. In all samples, cell viability was more than $85 \%$ and the purified cell count was 21 to 73 million cells. These consisted of mainly mononuclear hematopoietic stem cells. Finally, the purified cells were suspended in $10 \mathrm{~mL}$ saline solution and transferred to the cardiac catheterization laboratory in cold box with aseptic technique, as soon as possible after cell preparing $(12,13)$.

\subsection{Autologus Bone Marrow Derived Mononuclear Stem Cell In- jection}

We divided the $10 \mathrm{~mL}$ solution of purified cell in three parts (each one $3-4 \mathrm{~mL}$ ) for intracoronary injection in LAD, LCX and RCA. The procedures were done under conscious sedation, and stop-flow method was used, 3 main coronary arteries were accessed and infused by cell containing solution. We used over-the-wire coronary balloon catheters and 0.014 inch guide wire to steer the balloon into the selected coronary arteries and then infused cells through the central port of the balloon into the coronaries $(9,11)$.

To allow penetration and homing of the mononuclear stem cells through the endothelium, the balloon catheter was inflated about 2 atmospheres to completely stop the blood flow into the coronary artery for 2 - 3 minutes, with ECG monitoring. If significant ST elevation was observed, cell infusion was stopped and the balloon was deflated to reverse all the ECG changes. Then, cell infusion resumed after some minutes till total 3 - $4 \mathrm{~mL}$ of solution was infused in each of LAD, LCX and RCA. After the procedure, coronary angiography was done to determine the patency of the vessels.

\section{Results}

We enrolled 8 symptomatic patients including 5 girls and 3 boys. Demographic data are shown in Table 1 .

During the time of stop-flow circulation, transient non-significant ST-segment elevations were observed in all patients. But in one case LAD infusion was performed in two steps due to significant ST elevation (referee to method material). No other important adverse events such as arrhythmia, persistent ST elevation, bleeding or cardiogenic arrest or shock occurred during the procedure. Also, the coronary vessels had no stenosis or obstruction before or after the procedure.

After the procedure, in two inotrope dependent cases we could taper IV inotrope and discharge the patients with 


\begin{tabular}{|c|c|c|c|c|c|c|}
\hline Patients & Age, $y$ & Gender & NYHA Functional Class & Antifailure Medications & $\begin{array}{l}\text { Catecholamine and Milrinone } \\
\text { Just Before Injection }\end{array}$ & $\begin{array}{l}\text { Hospitalization Times in } \\
\text { Previous } 6 \text { Months }\end{array}$ \\
\hline $\mathbf{1}$ & 4 & Female & 4 & Yes & No & 4 \\
\hline 2 & 8 & Female & 4 & Yes & No & 3 \\
\hline 3 & 10 & Male & 4 & Yes & Yes & 2 \\
\hline 4 & 13 & Female & 4 & Yes & Yes & 3 \\
\hline 5 & 14 & Female & 4 & Yes & Yes & $\begin{array}{l}\text { IV inotrope dependent-more than } \\
1 \text { month hospitalization before } \\
\text { procedure }\end{array}$ \\
\hline 6 & 9 & Female & 4 & Yes & No & 3 \\
\hline 7 & 15 & Male & 4 & Yes & No & 4 \\
\hline
\end{tabular}

PO medication after 8 and 10 days. Heart failure functional class improved in 5 out of 8 patients (62\%) about one month after injection (change NYHA functional class to 2 or 3). Only one patient needed rehospitalisation during the 6 months of follow up. Duration of this hospitalization was also short (3 days). In 3 patients with persistent symptom in rest (NYHA functional class 4 ) we continued a high dose of anti-failure therapy. In addition to lack of improvement in functional class, none of them needed to be rehospitalized during 6 months.

In one patient without ejection fraction (EF) change, longitudinal strain and strain rate revealed improvement (Figures 1 and 2).

M-mode echocardiography findings of the patients are presented in Table 2 . This modality showed statistically significant improvement of ejection fraction (mean $24.8 \pm 8.3$ vs. $37.4 \pm 10.5$, P value $=0.028$ ) and shortening fraction 12.1 \pm 3.9 vs. $18.6 \pm 5.7$, P value $=0.026$, respectively $)$ and reduction of the LVID in systole (P value $=0.018)$ (Table 2 ).

Global longitudinal strain (GLS) and strain rate of the left ventricle of all patients (Figures 1 and 2) showed improvement of indices in all patients. Before the procedure and after 6 months of follow up, the mean GLS (-2.8 \pm 1.9 vs. $-5.2 \pm 3.9 ; \mathrm{P}$ value $=0.017)$ and GLS rate $(-0.3 \pm 0.1 \mathrm{vs.}-0.5 \pm$ $0.4 ;$ P value $=0.02$ ) showed a significant improvement .

Table 3 show the details of speckle tracking results in 6 regions. In spite of the improvement in the strain and $s$ strain rate after treatment in all regions, paired $t$-test analysis did not show a statistically significant difference between them.

\section{Discussion}

In the recent years, stem cells therapy as a bridging treatment in idiopathic DCM or in some cases as a rescue treatment has attracted the attention of many researchers and clinicians. In adult population, different methods and results of this solution that generally indicate the feasibility and effectiveness of this treatment have been described, but controversies persist $(14,15)$. For the pediatric age group controversies are more, and few clinical experiences, usually in limited case groups, have been reported. Most of these clinical experiences indicate positive results with regard to clinical and in some cases para-clinical finding $(2,4,14,16-18)$. This study showed that $62 \%$ of the patients have improvement of clinical condition even in inotrope dependent cases. The later finding (improvement in critically ill patients) was seen in early phase of stem cells injection, before the required time for stem cell regeneration and differentiation to cardiac cell. It indicates that bone marrow mononuclear cell (BMMNCs) infusion may improve the cardiac function by cytokine or other biological products in the bone marrow and not directly related to stem cell differentiation or new cardio-myocyte generation (19). Animal studies and some adult population studies in this area also propose indirect reparative mechanism by paracrine effects (19-22). Intracoronary infusion of unselected BMMNC has low retention rates of stem cells in comparison to other techniques such as selected CD34+ or mesenchymal stem cells infusion. This factor decreases the chance of cardiomyogenic differentiation in this technique, as well (23). Thus, it may be considered in critically ill patients, to benefit from reparative effect of BMMNCs injection as a rescue treatment, as in two of inotrope dependent patients in this study. We recommend further investigation of this finding in a larger randomized clinical trial.

In this study, clinical response was more obvious than echocardiographic changes; this finding has been confirmed in multiple similar studies in adult and pediatric 
Global Longitudinal Strain Changes

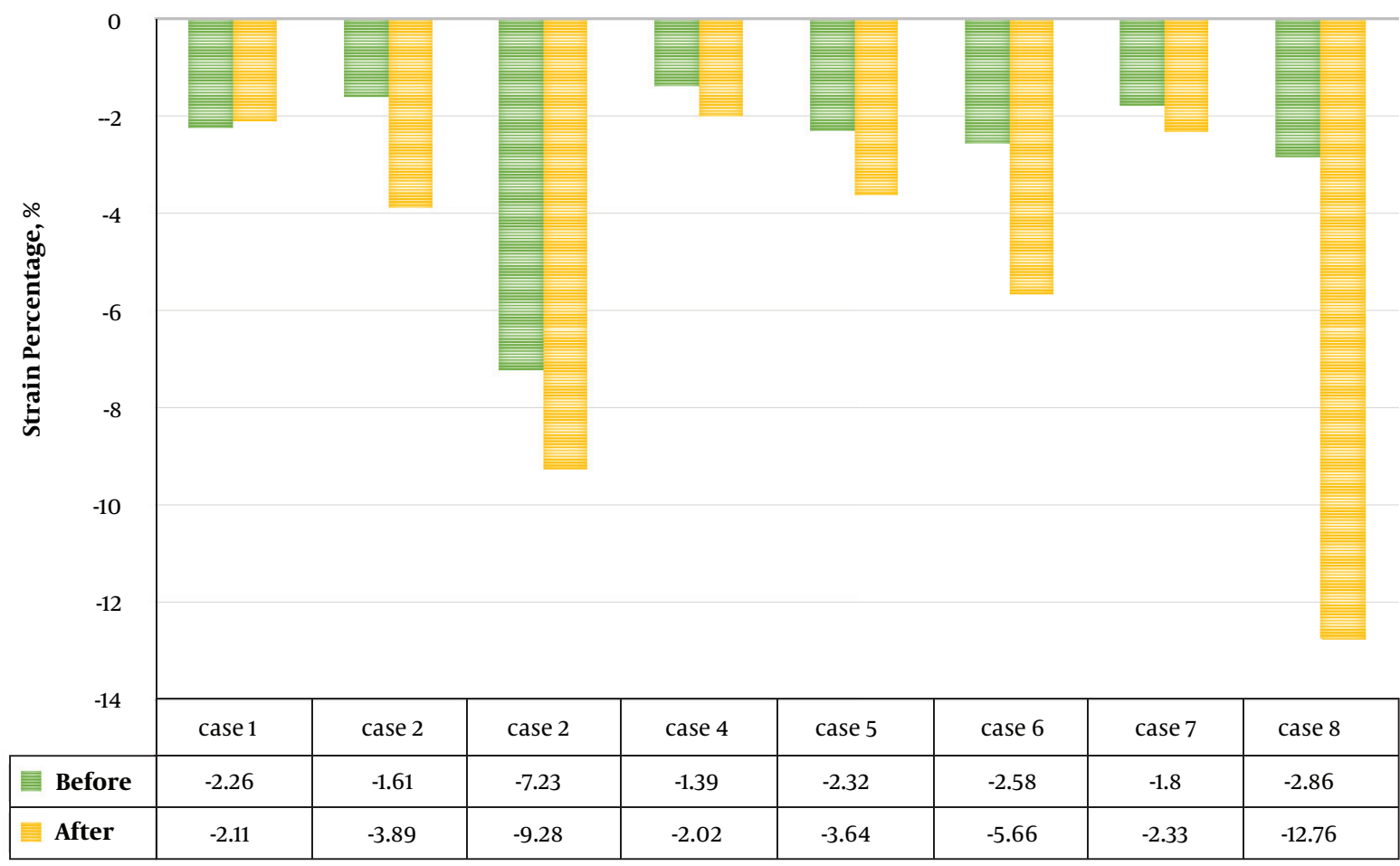

Figure 1. GLS of the patients, before and 6 months after the injection

\begin{tabular}{|c|c|c|c|c|c|c|c|c|}
\hline \multirow[t]{2}{*}{ Case No. } & \multicolumn{2}{|c|}{ LVIDD } & \multicolumn{2}{|c|}{ LVIDS } & \multicolumn{2}{|c|}{$\mathbf{E F}$} & \multicolumn{2}{|c|}{ FS } \\
\hline & Before & After & Before & After & Before & After & Before & After \\
\hline $\mathbf{1}$ & 3.85 & 4.03 & 3.52 & 3.39 & 19 & 34 & 9 & 16 \\
\hline 2 & 6.61 & 6.6 & 5.78 & 5.46 & 25 & 33 & 12 & 16 \\
\hline 3 & 4.22 & 3.75 & 3.57 & 1.05 & 33 & 40 & 16 & 20 \\
\hline 4 & 6.6 & 7.14 & 5.96 & 5.14 & 23 & 37 & 11 & 18 \\
\hline 5 & 7.1 & 6.1 & 6.2 & 5.5 & 12 & 40 & 7 & 22 \\
\hline 6 & 5.7 & 5.75 & 4.77 & 4.6 & 30 & 39 & 15 & 19 \\
\hline 7 & 7.07 & 6.73 & 6.44 & 6.27 & 19 & 19 & 9 & 9 \\
\hline 8 & 5.12 & 4.43 & 4.2 & 3.16 & 37 & 57 & 18 & 29 \\
\hline Total, mean \pm SD & $5.8 \pm 1.3$ & $5.6 \pm 1.3$ & $5.1 \pm 1.2$ & $4.3 \pm 1.7$ & $24.8 \pm 8.3$ & $37.4 \pm 10.5$ & $12.1 \pm 3.9$ & $18.6 \pm 5.7$ \\
\hline P value before vs. after & \multicolumn{2}{|c|}{0.07} & \multicolumn{2}{|c|}{0.018} & \multicolumn{2}{|c|}{0.028} & \multicolumn{2}{|c|}{0.026} \\
\hline
\end{tabular}

Abbreviations: EF, ejection fraction; LVIDD, left ventricular internal diameter in diastole; LVIDS, left ventricular internal diameter in systole; SF, shortening fraction.

age groups $(2,6,7,9,17,24)$. All patients had shorter hospitalization with improvement of NYHA functional class in $62 \%$ of patients. About $13 \%$ increase in $\mathrm{EF}$, was more than that in other similar studies; EF changes have had a wide variation in different reports, ranging from $0 \%$ to $21 \%$. Usu- ally, randomized clinical trials report fewer changes and more changes is reported by case series or pediatric age group studies $(8,14,24,25)$. Other M-mode indices had more subtle changes and especially LVEDD had minimum changes in different studies, similar to the non-significant 


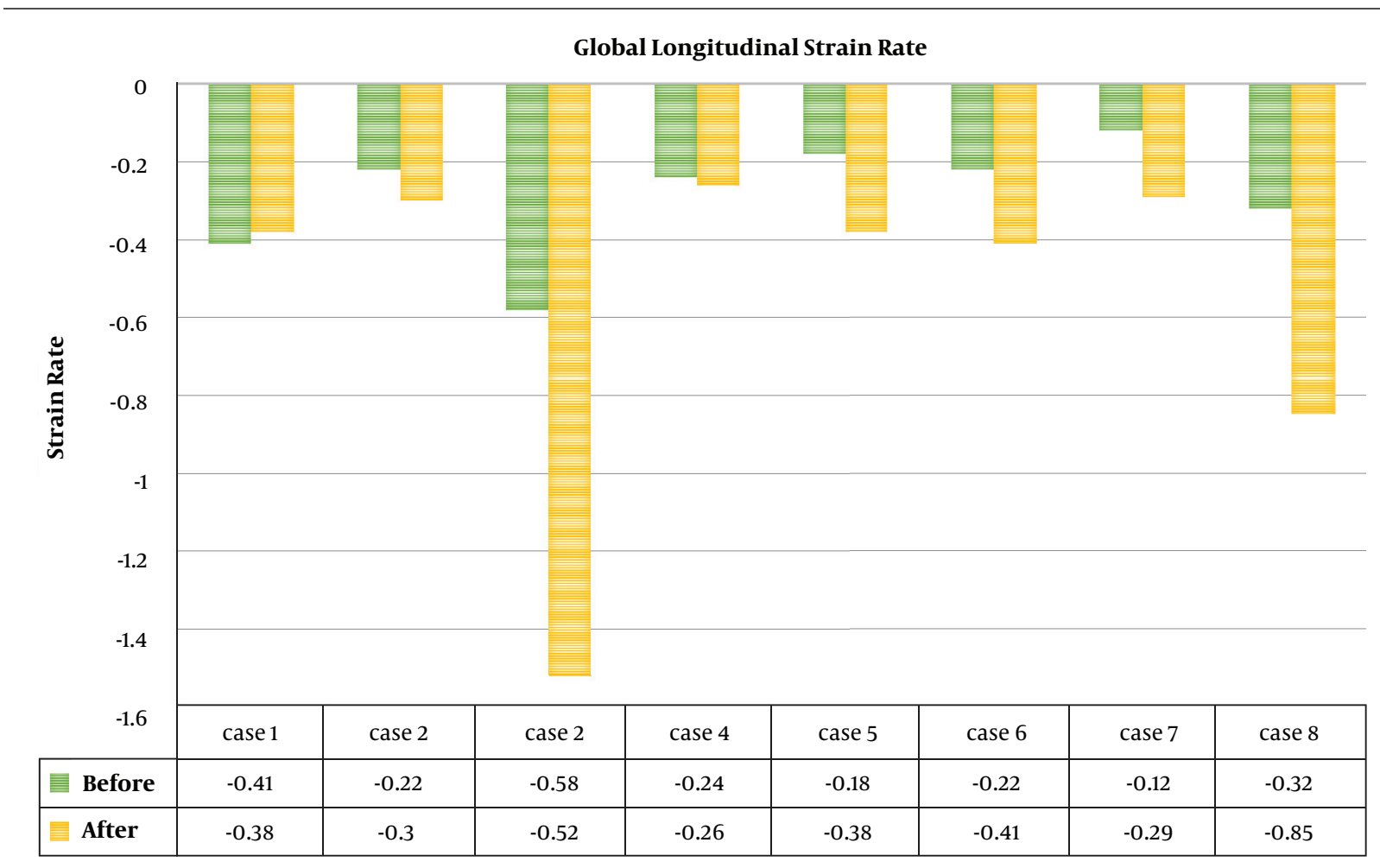

Figure 2. GLS rate of the patients, before and 6 months after the injection

\begin{tabular}{|c|c|c|c|c|c|c|}
\hline \multirow[t]{2}{*}{ Region } & \multicolumn{2}{|c|}{ Strain } & \multirow[t]{2}{*}{ P Value } & \multicolumn{2}{|c|}{ Strain Rate } & \multirow[t]{2}{*}{ PValue } \\
\hline & Before Treatment & Follow Up & & Before Treatment & Follow Up & \\
\hline Basal septal & $-2.8 \pm 2.2$ & $-5.6 \pm 3.9$ & 0.153 & $-0.35 \pm 0.19$ & $-0.75 \pm 0.64$ & 0.074 \\
\hline Middle septal & $-2.7 \pm 2.4$ & $-5 \pm 3.8$ & 0.157 & $-0.24 \pm 0.2$ & $-0.61 \pm 0.67$ & 0.083 \\
\hline Apical septal & $-3.2 \pm 2$ & $-5.4 \pm 4.9$ & 0.193 & $-0.29 \pm 0.30$ & $-0.6 \pm 0.54$ & 0.081 \\
\hline Basal lateral & $-3.1 \pm 1.8$ & $-6.2 \pm 4.9$ & 0.078 & $-0.38 \pm 0.12$ & $-0.56 \pm 0.46$ & 0.351 \\
\hline Middle lateral & $-2.5 \pm 2.4$ & $-5.4 \pm 4.5$ & 0.055 & $-0.27 \pm 0.23$ & $-0.45 \pm 0.31$ & 0.138 \\
\hline Apical lateral & $-2.3 \pm 2$ & $-4.9 \pm 4$ & 0.114 & $-0.22 \pm 0.15$ & $-0.38 \pm 0.40$ & 0.185 \\
\hline
\end{tabular}

decrease in this study $(8,14,24)$.

GLS showed improvement of strain and strain rate results. Segmental analysis showed most changes in the basal lateral region, but none of the 6 regions in the 4 chamber view had significant statistical changes. To the best of our knowledge, there is no report on pediatric cardiomyopathies that can be compared with our study. However, subtle changes in different regions which are globally increased in all regions may indicate non-dependent coronary territory effect of this treatment. As we mentioned in the results, one of the patients with clinically improved heart failure did not show increased ejection fraction and shortening fraction, while an increase in the global strain and strain rate was seen. It indicated that speckle tracking of these patients may result in more precise para-clinical findings that explain the clinical improvement of these patients. We recommend these patients be followed by speckle tracking echocardiography, and not only by $2 \mathrm{D}$ echocardiography.

There are controversies on the method of mononuclear stem cells injection, and some authors believe that trans-endocardial stem cell injection has a higher myocardial cell retention rate with higher success rate in comparison with trans-coronary injection $(2,25)$. Although our 
findings with intracoronary injection method were similar to their results, trans-endocardial injection seems appropriate for local myocardial dysfunction, especially in ischemic dilated cardiomyopathy in which hibernating myocardium (viable but dysfunctional myocardium) is presented and injection can be performed in these areas, precisely after cardiac mapping. In addition, selected BMMNCs, mesenchymal stem cell or cardiac stem cell are more prone to differentiation to the cardiomyogenic cell rather than unselected BMMNCs in different method of injection $(22,26)$.

Similar to many other studies, there was no serious complication during the procedure in our study, and this is not a new finding in pediatric or adult age groups $(2,8$, 19). Even critically ill patient in this study could tolerate the procedure. We need more investigation in this area, but based on many other studies in adult and case series in pediatric cases, the risk of these procedures is acceptable for most of the patients and could be considered as rescue treatment in critically ill patients $(2,9,11,26)$.

\subsection{Limitations of the Study}

The number of patients in our centers was limited (but acceptable for a pilot study) and larger studies can result in more precise findings. Larger clinical trials are needed to compare the efficacy of non-selected mononuclear stem cells injection with selected CD 34+ cells injection or other sources of stem cell.

\subsection{Conclusions}

This trial investigated the effect of mononuclear stem cells therapy in patients with dilated cardiomyopathy. We observed improvement in myocardial function in pediatric patients with dilated cardiomyopathy after intracoronary cell-therapy. The efficacy and safety of this method seems to be acceptable, and the results are promising. Speckle tracking echocardiography is a more precise method to follow the changes in these patients.

Hence, we suggest that mononuclear stem cells injection can be used for stabilization of some patients to defer heart transplantation, especially in inotrope-dependent or end-stage DCM patients.

\section{Acknowledgments}

The authors would like to thank Center for Development of Clinical Research of Nemazee Hospital, Shiraz University of Medical Sciences, and Dr. Nasrin Shokrpour for editorial assistance.

\section{Footnotes}

Authors' Contribution: Study concept and design and catheterization: Hamid Amoozgar, Hamid Mohammadi, Mohammad R. Edraki, and Maryam Ayatollahi. Analysis and interpretation of data: Hamid Amoozgar, Mohammad R. Edraki, Gholamhossein Ajami, and Mohammad Borzouee. Drafting of the manuscript: Amir Naghshzan, Kambiz Keshavarz, Fatehi Alwesabi, and Hamid Arabi. Critical revision of the manuscript for important intellectual content: Hamid Mohammadi, Mohammad R. Edraki, Nima Mehdizadegan, and Maryam Ayatollahi. Statistical analysis: Hamid Amoozgar, and Hamid Mohammadi.

Conflict of Interests: It is not declared by the authors.

Ethical Approval: This study was approved by Ethics Committee of Shiraz University of Medical Sciences, Shiraz, Iran on 2016-07-31 with ethics committee reference number: IR.SUMS.REC.1395.81 (https://www.irct.ir/trial/26782).

Funding/Support: It is not declared by the authors.

\section{References}

1. Theiss HD, David R, Engelmann MG, Barth A, Schotten K, Naebauer $\mathrm{M}$, et al. Circulation of CD34+ progenitor cell populations in patients with idiopathic dilated and ischaemic cardiomyopathy (DCM and ICM). Eur Heart J. 2007;28(10):1258-64. doi: 10.1093/eurheartj/ehm011. [PubMed: 17395679].

2. Bergmane I, Lacis A, Lubaua I, Jakobsons E, Erglis A. Follow-up of the patients after stem cell transplantation for pediatric dilated cardiomyopathy. Pediatr Transplant. 2013;17(3):266-70. doi: 10.1111/petr.12055. [PubMed: 23458132].

3. Almond CSD, Thiagarajan RR, Piercey GE, Gauvreau K, Blume ED, Bastardi HJ, et al. Waiting list mortality among children listed for heart transplantation in the United States. Circulation. 2009;119(5):71727. doi: 10.1161/CIRCULATIONAHA.108.815712. [PubMed: 19171850]. [PubMed Central: PMC4278666].

4. Mozid AM, Arnous S, Sammut EC, Mathur A. Stem cell therapy for heart diseases. Br Med Bull. 2011;98:143-59. doi: 10.1093/bmb/ldr014. [PubMed: 21596713].

5. Abdel-Latif A, Bolli R, Tleyjeh IM, Montori VM, Perin EC, Hornung CA, et al. Adult bone marrow-derived cells for cardiac repair: A systematic review and meta-analysis. Arch Intern Med. 2007;167(10):989-97. doi: 10.1001/archinte.167.10.989. [PubMed: 17533201].

6. Janssens SP. Mesenchymal cell therapy for dilated cardiomyopathy: Time to test the water. J Am Coll Cardiol. 2017;69(5):538-40. doi: 10.1016/j.jacc.2016.11.044. [PubMed: 28153109].

7. Seth S, Narang R, Bhargava B, Ray R, Mohanty S, Gulati G, et al. Percutaneous intracoronary cellular cardiomyoplasty for nonischemic cardiomyopathy: Clinical and histopathological results: The first-in-man ABCD (autologous bone marrow cells in dilated cardiomyopathy) trial. J Am Coll Cardiol. 2006;48(11):2350-1. doi: 10.1016/j.jacc.2006.07.057. [PubMed: 17161269].

8. Vrtovec B, Poglajen G, Lezaic L, Sever M, Domanovic D, Cernelc P, et al. Effects of intracoronary CD34+ stem cell transplantation in nonischemic dilated cardiomyopathy patients: 5-year follow-up. Circ Res. 2013;112(1):165-73. doi: 10.1161/CIRCRESAHA.112.276519. [PubMed: 23065358]. 
9. Zeinaloo A, Zanjani KS, Bagheri MM, Mohyeddin-Bonab M, Monajemzadeh M, Arjmandnia MH. Intracoronary administration of autologous mesenchymal stem cells in a critically ill patient with dilated cardiomyopathy. Pediatr Transplant. 2011;15(8):E183-6. doi: 10.1111/j.1399-3046.2010.01366.x. [PubMed: 20880092].

10. Ng PY, Sin WC, Ng AK, Chan WM. Speckle tracking echocardiography in patients with septic shock: A case control study(SPECKSS). Crit Care. 2016;20(1):145. doi: 10.1186/s13054-016-1327-0. [PubMed: 27177587]. [PubMed Central: PMC4867983].

11. Rupp S, Jux C, Bonig H, Bauer J, Tonn T, Seifried E, et al. Intracoronary bone marrow cell application for terminal heart failure in children. Cardiol Young. 2012;22(5):558-63. doi: 10.1017/S1047951112000066. [PubMed: 22329889].

12. Ayatollahi M, Soleimani M, Geramizadeh B, Imanieh MH. Insulinlike growth factor 1 (IGF-I) improves hepatic differentiation of human bone marrow-derived mesenchymal stem cells. Cell Biol Int. 2011;35(11):1169-76. doi: 10.1042/CBI20110016. [PubMed: 21910691].

13. Ayatollahi M, Geramizadeh B, Zakerinia M, Ramzi M, Yaghobi R, Hadadi $P$, et al. Human bone marrow-derived mesenchymal stem cell: A source for cell-based therapy. Int J Organ Transplant Med.2012;3(1):3241. [PubMed: 25013621]. [PubMed Central: PMC4089277].

14. Traverse JH, Henry TD, Ellis SG, Pepine CJ, Willerson JT, Zhao DX, et al. Effect of intracoronary delivery of autologous bone marrow mononuclear cells 2 to 3 weeks following acute myocardial infarction on left ventricular function: The LateTIME randomized trial. JAMA. 2011;306(19):2110-9. doi: 10.1001/jama.2011.1670. [PubMed: 22084195]. [PubMed Central: PMC3600981].

15. Hao M, Wang R, Wang W. Cell therapies in cardiomyopathy: Current status of clinical trials. Anal Cell Pathol (Amst). 2017;2017:9404057. doi: 10.1155/2017/9404057. [PubMed: 28194324]. [PubMed Central: PMC5282433 holders of Cellular Biomedicine Group (NASDAQ: CBMG)].

16. Beitnes JO, Gjesdal O, Lunde K, Solheim S, Edvardsen T, Arnesen H, et al. Left ventricular systolic and diastolic function improve after acute myocardial infarction treated with acute percutaneous coronary intervention, but are not influenced by intracoronary injection of autologous mononuclear bone marrow cells: A 3 year serial echocardiographic sub-study of the randomized-controlled ASTAMI study. Eur J Echocardiogr. 2011;12(2):98-106. doi: 10.1093/ejechocard/jeq116. [PubMed: 20851818].

17. Clifford DM, Fisher SA, Brunskill SJ, Doree C, Mathur A, Clarke MJ, et al. Long-term effects of autologous bone marrow stem cell treat- ment in acute myocardial infarction: Factors that may influence outcomes. PLoS One. 2012;7(5). e37373. doi: 10.1371/journal.pone.0037373. [PubMed: 22655042]. [PubMed Central: PMC3360027]

18. Nasseri BA, Kukucka M, Dandel M, Knosalla C, Choi YH, Ebell W, et al. Two-dimensional speckle tracking strain analysis for efficacy assessment of myocardial cell therapy. Cell Transplant. 2009;18(3):36170. doi: 10.3727/096368909788534924. [PubMed: 19558784].

19. Murry CE, Soonpaa $M H$, Reinecke $H$, Nakajima $H$, Nakajima HO, Rubart M, et al. Haematopoietic stem cells do not transdifferentiate into cardiac myocytes in myocardial infarcts. $\mathrm{Na}$ ture. 2004;428(6983):664-8. doi: 10.1038/nature02446. [PubMed: 15034593].

20. Steinhoff G, Nesteruk J, Wolfien M, Grosse J, Ruch U, Vasudevan P, et al. Stem cells and heart disease - Brake or accelerator? Adv Drug Deliv Rev. 2017;120:2-24. doi: 10.1016/j.addr.2017.10.007. [PubMed: 29054357].

21. Traverse JH. Is there a role for intravenous stem cell delivery in nonischemic cardiomyopathy? Circ Res. 2017;120(2):256-8. doi: 10.1161/CIRCRESAHA.116.310342. [PubMed: 28104762]. [PubMed Central: PMC5260805].

22. Cambria E, Pasqualini FS, Wolint P, Gunter J, Steiger J, Bopp A, et al. Translational cardiac stem cell therapy: Advancing from firstgeneration to next-generation cell types. NPJ Regen Med. 2017;2:17. doi: 10.1038/s41536-017-0024-1. [PubMed: 29302353]. [PubMed Central: PMC5677990].

23. Lezaic L, Haddad F, Vrtovec B, Wu JC. Imaging cardiac stem cell transplantation using radionuclide labeling techniques: Clinical applications and future directions. Methodist Debakey Cardiovasc J. 2013;9(4):218-22. [PubMed: 24298314]. [PubMed Central: PMC3846077].

24. Lacis A. Management of idiopathic dilated cardiomyopathy with intramyocardial stem cell transplantation in children: A retrospective study of 7 patients. Sci J Clin Med. 2013;2(4):129. doi: 10.11648/j.sjcm.20130204.12.

25. Vrtovec B, Poglajen G, Lezaic L, Sever M, Socan A, Domanovic D, et al. Comparison of transendocardial and intracoronary CD34+ cell transplantation in patients with nonischemic dilated cardiomyopathy. Circulation. 2013;128(11 Suppl 1):S42-9. doi: 10.1161/CIRCULATIONAHA.112.000230. [PubMed: 24030420].

26. Selem SM, Kaushal S, Hare JM. Stem cell therapy for pediatric dilated cardiomyopathy. Curr Cardiol Rep. 2013;15(6):369. doi: 10.1007/s11886013-0369-z. [PubMed: 23666883]. [PubMed Central: PMC4128369]. 